\title{
Recombinant programmed cell death 1 inhibits psoriatic inflammation in imiquimod-treated mice
}

\author{
SHIGUANG PENG ${ }^{1 *}$, MEI CAO $^{1 *}$, XIAOYING SUN ${ }^{2,3}$, YAQIONG ZHOU $^{3}, \mathrm{CHU}$ YEN CHEN $^{4}$, \\ TIAN MA ${ }^{2}$, HONGJIN LI ${ }^{3}$, BIN LI ${ }^{2,3}$, BO ZHU ${ }^{4}$ and $\mathrm{XIN} \mathrm{LI}^{2,3}$ \\ ${ }^{1}$ Department of Dermatology, Beijing Chao-yang Hospital, Capital Medical University, Beijing 100020; ${ }^{2}$ Department of \\ Dermatology, Yueyang Hospital of Integrated Traditional Chinese and Western Medicine, Shanghai University of \\ Traditional Chinese Medicine, Shanghai 200437; ${ }^{3}$ Institute of Dermatology, Shanghai Academy of \\ Traditional Chinese Medicine, Shanghai 201203, P.R. China; ${ }^{4}$ Department of Cancer Immunology and Virology, \\ Dana-Farber Cancer Institute, Harvard Medical School, Boston, MA 02115, USA
}

Received December 10, 2019; Accepted May 4, 2020

DOI: $10.3892 /$ ijmm.2020.4612

\begin{abstract}
Psoriasis is a common chronic inflammatory skin disease. Programmed cell death ligand 1 (PD-L1) and programmed cell death 1 (PD-1) are expressed on immune cells in a number of chronic inflammatory diseases. However, a limited number of studies have investigated the expression and function of the PD-L1 and PD-1 pathway in psoriatic inflammation. The present study used human psoriasis samples and imiquimod-induced murine psoriasis models to investigate the potential role of PD-1 in the modulation of psoriatic inflammation. The results demonstrated that inhibition of PD-1 function with antibodies promoted psoriasis development. PD-1-fragment crystallizable (PD-1-Fc) treatment inhibited psoriatic inflammation and exhibited additive effects with anti-tumor necrosis factor $\alpha$ therapy in imiquimod-induced mouse psoriasis, suggesting that PD-1-Fc treatment may serve as a new therapeutic strategy for psoriasis.
\end{abstract}

Correspondence to: Dr Shiguang Peng, Department of Dermatology, Beijing Chao-yang Hospital, Capital Medical University, 8 Gongti Nanlu, Chaoyang, Beijing 100020, P.R. China E-mail: gavin_psg@163.com

Dr Xin Li, Department of Dermatology, Yueyang Hospital of Integrated Traditional Chinese and Western Medicine, Shanghai University of Traditional Chinese Medicine, 110 Ganhe Road, Hongkou, Shanghai 200437, P.R. China

E-mail: 13661956326@163.com

${ }^{*}$ Contributed equally

Key words: programmed cell death 1, psoriasis, recombinant $\mathrm{PD}-1-\mathrm{Fc}$

\section{Introduction}

Patients with psoriasis exhibit chronic skin inflammation, which is characterized by thick and scaly plaques $(1,2)$. Psoriasis is an autoimmune disease mediated by $\mathrm{T}$ cells; studies using a range of immune antagonists and human skin xenografts have identified that $\mathrm{CD}^{+}$and $\mathrm{CD} 4^{+} \mathrm{T}$ cells infiltrate into psoriatic skin lesions (1,3-6).

Programmed cell death 1 (PD-1), a member of the superfamily of cytotoxic T-lymphocyte-associated protein 4 (CTLA-4) immunoglobulins involved in immune regulation, has attracted increasing attention in immune disease (7). PD-1 activation functions as a rheostat to regulate immune activities, inhibiting T-cell activation (8). PD-1 is activated by binding its ligands, programmed cell death ligand 1 (PD-L1) and PD-L2 (9-11), which signal T cells to inhibit cell proliferation, cytotoxicity and cytokine production (12). PD-1 cannot normally be detected on the surface of resting T cells; however, following activation by ligand binding to T-cell receptors, activated T cells express high levels of PD-1 $(13,14)$. PD-1 signaling also affects cytokine production, including interferon $\gamma($ IFN- $\gamma$ ), interleukin 2 (IL-2) and tumor necrosis factor $\alpha(\mathrm{TNF}-\alpha)(12)$. Mice lacking PD-1 are resistant to viral infections, tumor growth and metastasis (15-17). Inhibiting PD-1 or its ligand PD-L1 has demonstrated promising benefits in metastatic melanoma treatment by overcoming the immunosuppressive tumor microenvironment and, consequently, has been approved by FDA for use in patients (18-20).

Traditional therapeutics for patients with psoriasis, including topical agents, systemic therapies and phototherapy, are not always sufficiently satisfactory; topical agents frequently result in short-term outcomes, and effective phototherapy treatment demands high requirements for clinician expertise and techniques to prevent skin erythema, photoaging or burning by inadequate choice of phototherapy types, parameters or unnecessary exposure $(2,21)$. Despite the demonstrated efficacy of biologic immune therapeutics in psoriasis treatment, which consist of two main classes that target $\mathrm{T}$ cells and cytokines, inconsistent efficacy is still an 
issue in clinical trials (22). To maximize the immunotherapeutic efficacy of psoriasis treatments, there is an urgent need to understand the predominant mechanisms of pathogenesis to provide experimental support for innovative treatments and rational combinations.

The activation of PD-1 signaling has previously been used to block T-cell activation, proliferation and cytotoxicity $(8,23)$. In addition, a previous study has demonstrated that PD-1 upregulation occurs in mouse psoriatic inflammatory skin induced by imiquimod (IMQ) (24). Treatment with recombinant PD-L1 protein significantly suppresses IMQ-induced psoriasis (25). Additionally, PD-1-null mice exhibit severe psoriatic inflammation (24). Thus, the hypothesis of the present study was that PD-1-targeted therapies may represent a promising new therapeutic strategy in psoriasis treatment.

\section{Materials and methods}

Characteristics of patients with psoriasis. Patients with psoriasis vulgaris were diagnosed according to characteristic skin changes and histopathological features. Prior to skin biopsy collection, systemic anti-psoriasis medications or ultraviolet phototherapy were discontinued for at least 8 weeks, and topical anti-psoriasis medications were discontinued for at least 4 weeks. No evidence of autoimmune disease other than psoriasis, malignant tumor and active viral or bacterial infection was present at the time of patient recruitment. Skin biopsies were collected from 10 patients [lesion skin; $6(60 \%)$ males, 4 (40\%) females; age, 30-72 years; mean age, 49 years] for IHC staining. The inflammatory level of psoriatic lesions was evaluated using The Psoriasis Area and Severity Index (PASI; range, 0-72) (26), which included four body regions: The head (h), trunk (t), upper extremities (u) and lower extremities (1); and the levels of erythema (E), infiltration (I), desquamation (D) and body surface area (A). The degree of severity was defined as 0 (no symptoms), 1 (slight), 2 (moderate), 3 (marked), or 4 (very marked), with the surface area defined as $1(<10 \%), 2(10-29 \%), 3(30-49 \%), 4(50-69 \%), 5(70-89 \%)$ or 6 (90-100\%). The PASI was calculated using the following formula: PASI $=0.1 \times\left(E_{h}+I_{h}+D_{h}\right) \times A_{h}+0.2 \times\left(E_{u}+I_{u}+D_{u}\right)$ $\mathrm{x} A_{u}+0.3 \times\left(E_{t}+I_{t}+D_{t}\right) \times A_{t}+0.4 \times\left(E_{1}+I_{1}+D_{1}\right) \times A_{1}(26)$. All participants signed informed consent prior to enrollment. The study was approved by the Beijing Chaoyang Hospital Scientific and Ethics Committee (approval no. 2016-11-4-5) and was conducted according to the Declaration of Helsinki.

Animal experiments. For all the mouse experiments, C57BL/6 mice (8-12 weeks old; Jackson Laboratory) were treated every day with a topical IMQ cream $(62.5 \mathrm{mg}$ in 5\%; 3M Company) on the backs and ears, whereas the control mice were treated with Vaseline Lanette cream (Fagron, Inc.), and all mice were observed for the following 8 consecutive days as previously described (27). A total of 180 mice were used in this experiment. PASI scoring was used to quantify the erythema, thickness and scaling independently (score range, $0-4$ ). The total score was calculated as previously described (27). The experimental mice were maintained under pathogen-free conditions, with ad libitum food and water. Mice were euthanized by inhalation of $\mathrm{CO}_{2}$ in a controllable manner at a flow rate of $15 \%$ volume displacement per minute, and the skin tissues were obtained and analyzed on the indicated days as described below.

Mouse in vivo experimental procedures. In the neutralizing anti-PD-1 mAb experiment, mice (8-12 weeks old) were intraperitoneally injected with $200 \mu \mathrm{g}$ anti-PD-1 (RMP1-14) $(n=20)$ or $\operatorname{IgG}(n=20)$ daily for 7 days starting when IMQ treatment was initiated. A total of 40 mice were used for this experiment. In the PD-1-Fc and anti-TNF- $\alpha$ intervention experiment, mice of the same age were intraperitoneally injected with $50 \mu \mathrm{g}$ PD-1-Fc and/or anti-TNF- $\alpha$ on day 0 and day 3, starting at IMQ treatment initiation. Each individual group had 20 mice ( 5 mice per time point), with 80 mice in total used for this experiment. All mice were monitored daily, and ear thickness was measured with a dial thickness gauge caliper daily. Mice were euthanized by inhalation of $\mathrm{CO}_{2}$, and the tissues were obtained and analyzed on the indicated day as described. All mouse experiments were approved by the Institutional Animal Care and Use Committee at Beijing Chaoyang Hospital in Capital Medical University in Beijing China (approval no. 2016-A-177).

Single-cell suspension preparation and flow cytometry. The isolated skin-draining inguinal lymph nodes from the mice were mashed with frosted glass slides and filtered through a $70-\mu \mathrm{m}$ cell strainer to produce a single-cell suspension $\left(1 \times 10^{7}\right.$ cells $\left./ \mathrm{ml}\right)$. The single-cell suspension was fixed with $2 \%$ paraformaldehyde for $15 \mathrm{~min}$ at room temperature prior to blocking with mouse $\mathrm{IgG}$ for $30 \mathrm{~min}$ on ice. Subsequently, the cells $\left(1 \times 10^{6}\right.$ in $\left.100 \mu \mathrm{l}\right)$ were incubated with anti-CD45 PerCP-Cy5.5 (cat. no. 45-0451-82; Invitrogen; Thermo Fisher Scientific, Inc.), anti-CD4 FITC (cat. no. RM4-5; BD Biosciences), anti-CD8 PE (cat. no. 553032; BD Biosciences) and anti-PD-1 PE-Cy7 (cat. no. 25-9985-82; Invitrogen; Thermo Fisher Scientific, Inc.) antibodies on ice for $1 \mathrm{~h}$. The cells were analyzed with an LSRII flow cytometer (BD Biosciences), and the data were analyzed with FlowJo software v10 (FlowJo, LLC).

Reverse transcription-quantitative (RT-q)PCR. Mouse skin was isolated for the extraction of total RNA using the RNeasy Mini kit (cat. no. 74104; Qiagen GmbH). The cDNA was synthesized with SuperScript II Reverse Transcriptase (Invitrogen; Thermo Fisher Scientific, Inc.) with dNTPs and poly(A) oligo(dT $)_{25}$ as a template primer at $42^{\circ} \mathrm{C}$ for $50 \mathrm{~min}$. A total of 40 ng cDNA was used as the template for the RT-qPCR assay with SYBR ${ }^{\circledR}$ Green PCR master mix (Applied Biosystems; Thermo Fisher Scientific, Inc.) in a 25- $\mu 1$ reaction system using a Quantstudio 12K Flex qPCR System (Thermo Fisher Scientific, Inc.) under the following thermocycling conditions: Denaturation at $95^{\circ} \mathrm{C}$ for $15 \mathrm{sec}$ and annealing/extension at $60^{\circ} \mathrm{C}$ for $1 \mathrm{~min}$ for total 40 cycles. Control RT-qPCR was performed using the master mix without reverse transcriptase. The relative gene expression levels were normalized to the expression of Gapdh. The comparative Ct method used was previously described (28). QPCR was performed three times.

The relative transcript levels of IL17, IFN- $\gamma$, IL-22, and TNF $\alpha$ were determined by RT-qPCR as previously described $(29,30)$. The primers used were as follows: Mouse IL17 forward, 5'-TTTAACTCCCTTGGCGCAAAA-3' 
and reverse, 5'-CTTTCCCTCCGCATTGACAC-3'; mouse IFN- $\gamma$ forward, 5'-ATGAACGCTACACACTGCATC-3' and reverse, 5'-CCATCCTTTTGCCAGTTCCTC-3'; mouse TNF $\alpha$ forward, 5'-CCCTCACACTCAGATCATCTTCT-3' and reverse, 5'-GTCACGACGTGGGCTACAG-3'; mouse IL22 forward, 5'-ATGAGTTTTTCCCTTATGGGGAC-3' and reverse, 5'-GCTGGAAGTTGGACACCTCAA-3'; and mouse Gapdh forward, 5'-TGTGTCCGTCGTGGATCTGA-3' and reverse, 5'-TTGCTGTTGAAGTCGCAGGAG-3'.

Antibodies, cytokines and in vivo treatment fusion proteins. The neutralizing monoclonal antibody (mAb) against PD-1 (clone RMP1-14; cat. no. BE0146) and Rat IgG2a (clone 2A3; cat. no. BE0089) in vivo were purchased from Bio X Cell. The PD-1-Fc protein (cat. no. 50124-M03H) was obtained from Sino Biological, Inc. Anti-mouse TNF- $\alpha$ (clone XT3.11; cat. no. BE0058) $\mathrm{mAb}$ was purchased from Bio X Cell. Anti-CD3 (cat. no. sc-20047), anti-CD8 (cat. no. sc-7188) and anti-CD4 (cat. no. sc-7219) antibodies were purchased from Santa Cruz Biotechnology, Inc. Anti-PD-1 and CD279 (cat. nos. PA5-2035 and PA5-32543) antibodies were purchased from Thermo Fisher Scientific, Inc., and the anti-PD-1 (clone J43; cat. no. 11-9985-81) antibody was purchased from eBioscience.

Histology and immunohistochemical (IHC) staining. Patient biopsies and mouse skin samples were fixed in formalin at room temperature for $24 \mathrm{~h}$ and embedded in paraffin. Hematoxylin and eosin (H\&E) staining was performed as previously described (29). IHC staining was performed as previously described (29) with anti-CD4, anti-CD8 and anti-PD-1 antibodies. An Olympus light microscope was used to examine the slides. Two independent researchers analyzed the H\&E and IHC staining slides. Epidermal thickness was assessed by quantification of keratinocyte numbers in the epidermis. Cells positive for CD4, CD8 and PD-1 were quantified as the mean number of positive cells in five high power fields (original magnification, $\mathrm{x} 400$ ).

Western blotting and ELISA. Mouse back skin with psoriatic lesions after IMQ treatment for 6 days was isolated and lysed with RIPA buffer and protease inhibitor cocktail (Thermo Fisher Scientific, Inc.), followed by homogenization with a D1000 Handheld Homogenizer (Benchmark Scientific, Inc.) for ELISA with the IL-17 Mouse ELISA kit (cat. no. BMS6001; Thermo Fisher Scientific, Inc.) and IL-23 Mouse ELISA kit (cat. no. BMS6017; Thermo Fisher Scientific, Inc.) according to the manufacturer's instructions.

The skin lysis protein concentration was measured with the Braford Protein Assay kit I (Bio-Rad Laboratories, Inc.), and $50 \mu \mathrm{g}$ total protein of each sample was loaded into each lane and separated with $12 \%$ SDS-PAGE. After transfer onto a PVDF membrane, 5\% (weight/volume) 5\% BSA (Sigma-Aldrich; Merck KGaA) was used for blocking at room temperature for $1 \mathrm{~h}$, and then anti-IL17 (1:1,000, cat. no. ab218013; Abcam), anti-IL23 (1:400, cat. no. ab45420; Abcam), and the control horseradish peroxidase (HRP)-conjugated anti- $\beta$-actin (1:4,000, cat. no. ab49900, Abcam) antibodies were used to blot the membranes at $4^{\circ} \mathrm{C}$ overnight. After the 3 washes with $1 \mathrm{X}$ TBS buffer with $1 \%$ Tween-20 (TBST), a goat anti-rabbit IgG secondary antibody (cat. no. 1706515; Bio-Rad Laboratories,
Inc.) was used to blot the membrane at room temperature for $2 \mathrm{~h}$. Subsequently, 1X TBST was used to wash the membranes again prior to incubation with Pierce SuperSignal chemiluminescent substrate (Thermo Fisher Scientific, Inc.). The membranes were visualized by autoradiography into clear-blue X-ray film (cat. no. 34089; Thermo Fisher Scientific, Inc.), and the densitometry analysis was performed with ImageJ 1.8.0 (National Institutes of Health).

Statistical analysis. The experiments were repeated three times. Data are presented as the mean \pm SD. Statistical analysis was performed using GraphPad Prism 7 (GraphPad Software, Inc.). Statistical significance was analyzed by a two-tailed unpaired Student's t-test. Correlation was determined with Pearson's correlation coefficient. For comparing multiple groups, one-way ANOVA and Tukey's post hoc test was performed. $\mathrm{P}<0.05$ was considered to indicate a statistically significant difference.

\section{Results}

PD-1 is upregulated and correlates with markers of psoriatic inflammation. Immunohistochemical staining was performed on patient psoriatic tissue samples using specific anti-PD-1 antibodies. The expression of PD-1 was detectable in all psoriatic samples and was enhanced with increasing psoriatic inflammation (Fig. 1A). In addition, the numbers of $\mathrm{CD}^{+}$ (Fig. 1B) and $\mathrm{CD}^{+}$(Fig. 1C) $\mathrm{T}$ cells increased in patients with high levels of psoriatic lesions. These results indicated an inflammation-associated role of PD-1 in psoriasis.

To identify the associations among epidermal hyperplasia, inflammation and PD-1 expression, epidermal thickness was measured by quantifying the keratinocyte number in the epidermis in five different regions to indicate psoriatic inflammation (31). The number of PD-1+ cells was significantly correlated with the number of keratinocytes (Fig. 1D), which suggested that $\mathrm{PD}-1^{+}$cells were associated with the progression of skin inflammation. Furthermore, the number of PD-1 ${ }^{+}$ cells was significantly correlated with the number of $\mathrm{CD}^{+}$ and $\mathrm{CD}^{+} \mathrm{T}$ cells (Fig. 1E and F). Collectively, these results indicated that PD-1 expression levels were associated with skin inflammation in psoriasis.

$P D-1$ is upregulated in IMQ-treated mouse T cells. An IMQ-induced mouse psoriasis model was used to determine PD-1 expression. The representative skin inflammatory lesion was observed between days 0 and 8 (Fig. 2A). Inflammation was also indicated by the thickness of skin determined by $\mathrm{H} \& \mathrm{E}$ staining of epidermal samples from the backs and ears of the mice (Fig. 2B).

To analyze immune cell population changes, skin-draining lymph nodes were collected to detect the $\mathrm{CD} 4^{+}$and $\mathrm{CD} 8^{+}$ T-cell populations in the IMQ-induced psoriasis mouse model using flow cytometry. The results demonstrated that the percentages of $\mathrm{CD} 4^{+}$and $\mathrm{CD} 8^{+} \mathrm{T}$ cells within the $\mathrm{CD} 45^{+}$cells increased following treatment with IMQ compared with those from mice treated with DMSO (Fig. 2C and D). In addition, the $\mathrm{PD}-\mathrm{1}^{+} \mathrm{CD} 4^{+}$population was significantly increased in IMQ-treated mice compared with those treated with DMSO (Fig. 2E and F). These results indicated that the level of PD-1 
A

B

C

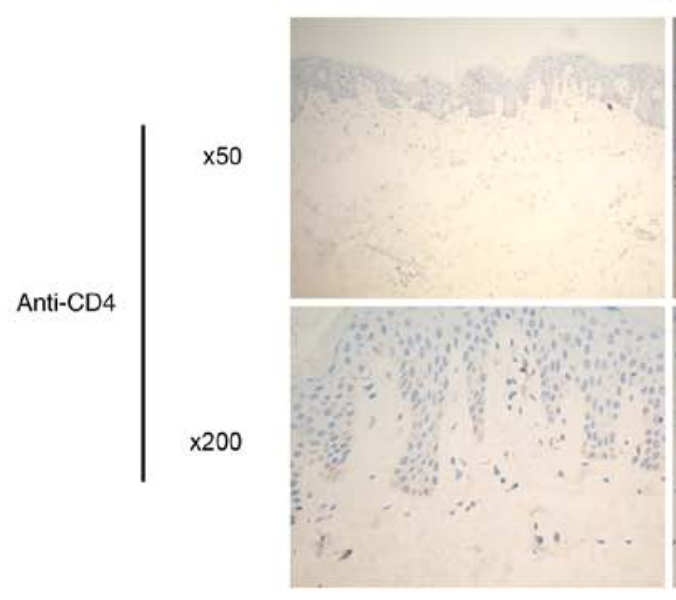

$\times 50$

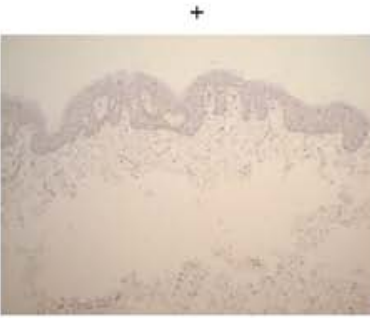

$\times 200$

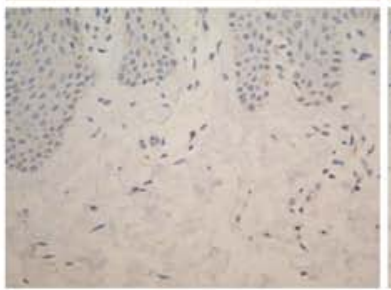

$\times 200$

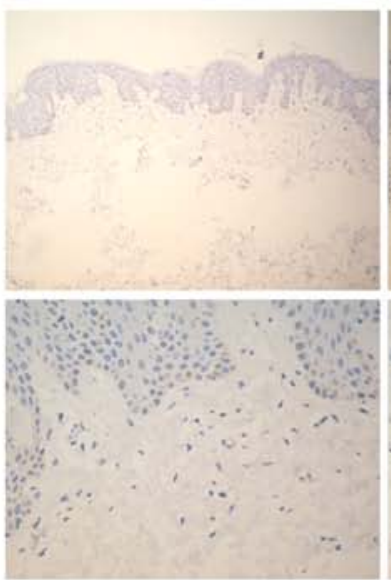

Psoriasis lesion inflammation leve
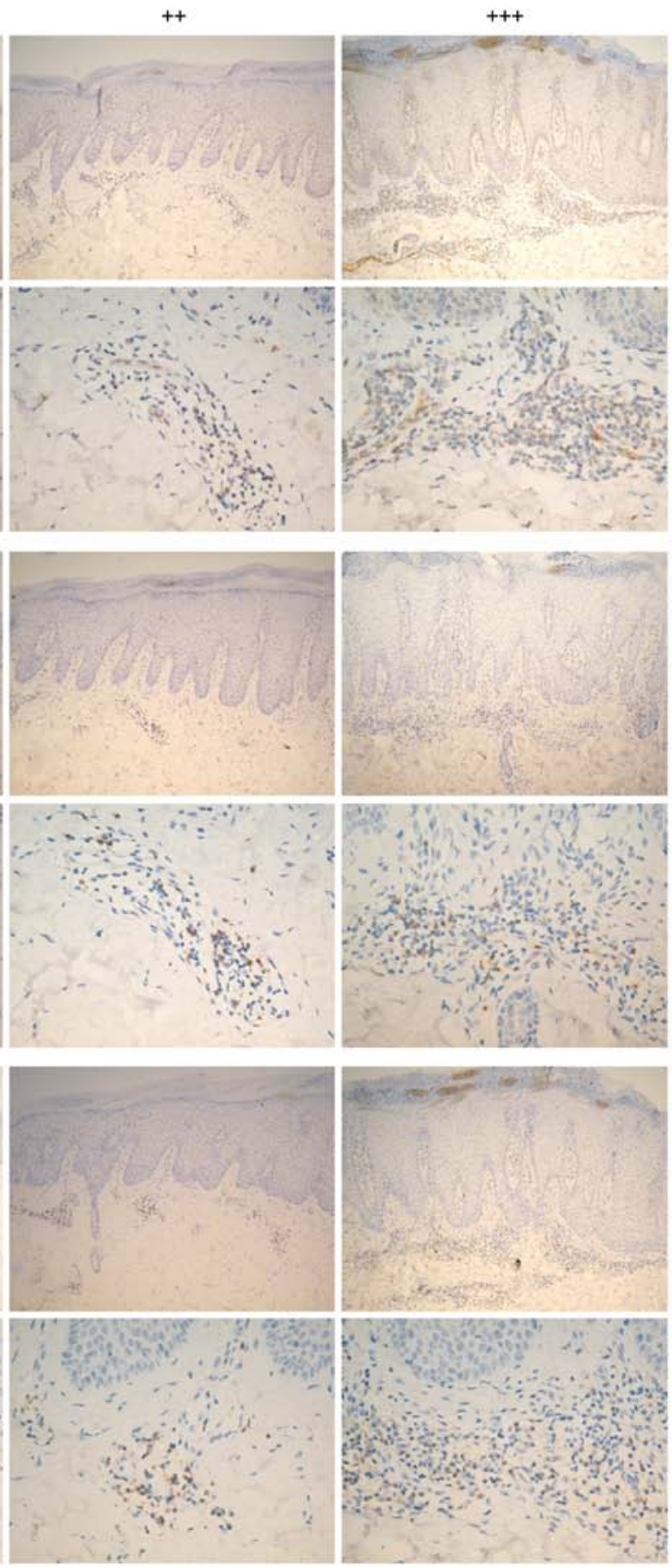

D

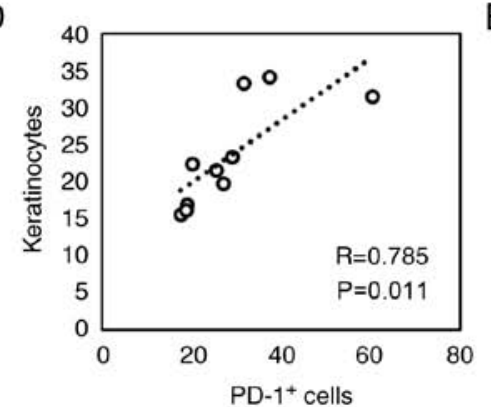

E

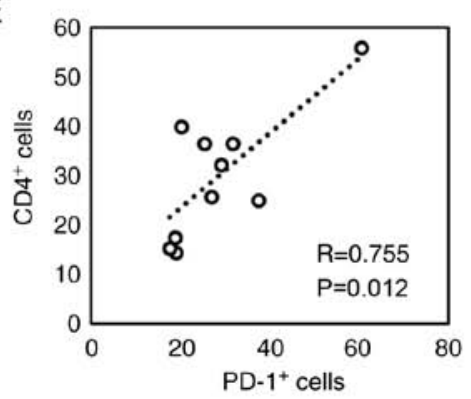

$\mathrm{F}$

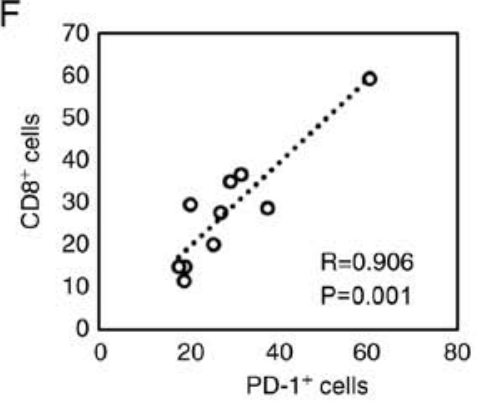

Figure 1. Upregulation of PD-1 expression in psoriatic lesions. (A-C) Psoriatic lesions from patients with different inflammation levels were assayed for (A) $\mathrm{PD}-1^{+},(\mathrm{B}) \mathrm{CD}^{+}(\mathrm{C})$ and $\mathrm{CD} 4^{+} \mathrm{T}$ cells by immunohistochemical staining. Representative immunohistochemical staining images from one of 10 psoriasis biopsy specimens are presented. (D-F) $\mathrm{CD} 4^{+}$and $\mathrm{CD} 8^{+} \mathrm{T}$ cells and PD-1 $1^{+}$lymphocytes were quantified, and the mean number of positive cells was determined per high-power field imaged. Pearson's correlation coefficients were calculated for the correlations between (D) keratinocytes and PD- $1^{+}$cells, (E) CD4 ${ }^{+}$and PD- $1^{+}$cells, and (F) $\mathrm{CD}^{+}$and $\mathrm{PD}-1^{+}$cells. $\mathrm{N}=10$. PD-1, programmed cell death 1. 
A

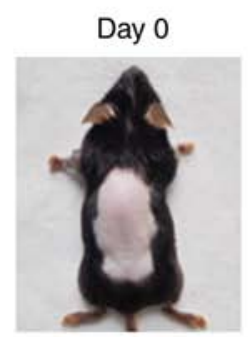
Imiquimod-induced psoriasis-like mouse skin inflammation
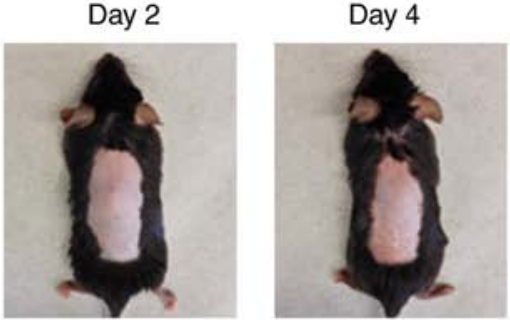

Day 6

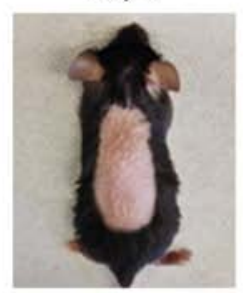

Day 8



B Imiquimod-induced psoriasis-like mouse skin inflammation
Day 0
Day 2
Day 4
Day 6

Day 8

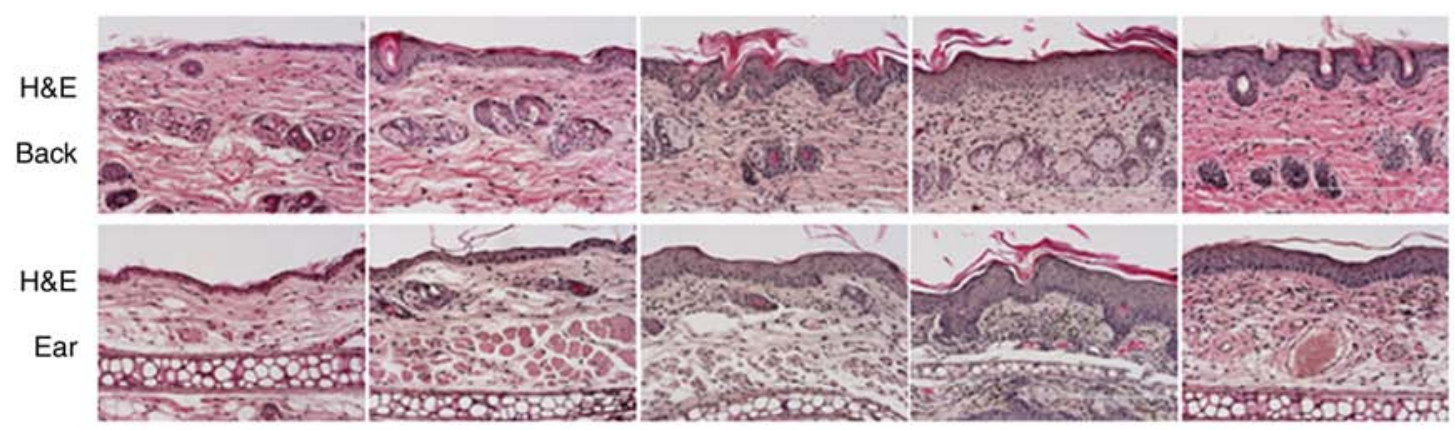

C

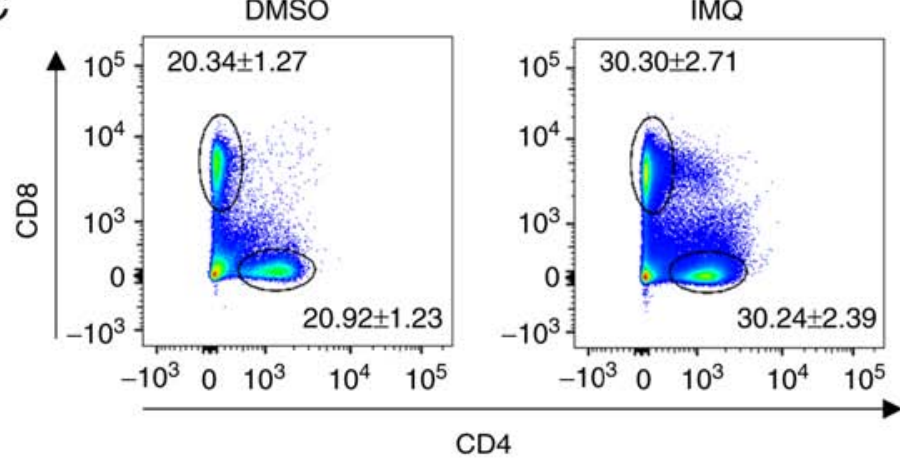

E



D
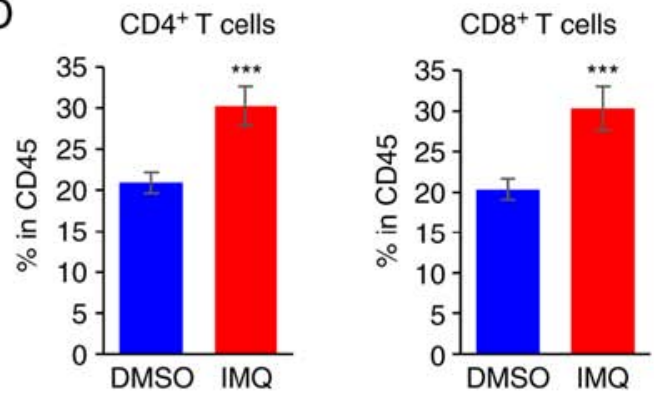

F
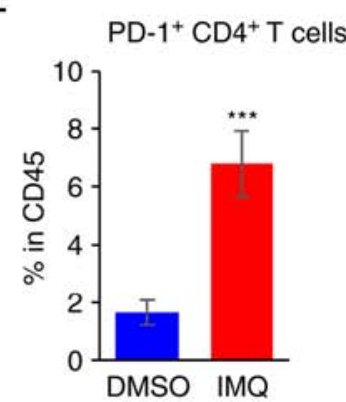

Figure 2. PD-1 levels in IMQ-induced psoriasis. (A) Phenotypic presentation of IMQ-induced mouse dorsal skin at the indicated time points. (B) Representative histopathological staining of IMQ-induced mouse psoriasis at the indicated time points. $\mathrm{N}=5$ at each time point. (C and D) Representative plots and quantification of flow cytometry analysis for $\mathrm{CD} 4^{+}$and $\mathrm{CD} 8^{+} \mathrm{T}$ cell percentages among total $\mathrm{CD} 45^{+}$cells in the skin-draining lymph nodes isolated from mice on day 6 . (E and F) Representative plots and quantification of flow cytometry analysis for the percentage of PD- $1^{+} \mathrm{CD} 4^{+}$cells in the skin-draining lymph nodes isolated from mice on day $6 . \mathrm{N}=5 .{ }^{* * * *} \mathrm{P}<0.001$ vs. DMSO. $\mathrm{PD}-1$, programmed cell death $1 ; \mathrm{IMQ}$, imiquimod.

increased in psoriatic lesions, suggesting that PD-1 may serve a role in the modulation of psoriatic inflammation.

Anti-PD-1 treatment enhances psoriatic inflammation. To analyze PD-1 signaling in psoriasis progression in vivo, a
PD-1-targeting intervention was used to treat IMQ-induced mouse psoriasis. Specifically, $200 \mu \mathrm{g} /$ day neutralizing $\mathrm{mAb}$ against PD-1 was used to treat the IMQ-induced mice. Isotype-matched IgG was used as a negative control. PASI was determined every day to quantify the psoriatic inflammation 
and evaluate the progression of psoriasis (27). The results demonstrated that skin inflammation increased following IMQ treatment for 6 days and decreased after IMQ treatment for 8 days, and that anti-PD-1-treated mice exhibited exacerbated psoriatic lesions and higher cumulative PASI sores compared with those in the control group (Fig. 3A and B). Epidermal thickness for the PASI score, which indicates the level of psoriatic inflammation, was assessed using histopathological staining of the back skin psoriatic lesions (Fig. 3B and C). The results demonstrated increased inflammatory immune cell populations in mice treated with anti-PD-1 compared with those in the $\mathrm{IgG}$ group. In addition, compared with mice treated with $\mathrm{IgG}$, mice treated with anti-PD-1 exhibited increased percentages of $\mathrm{CD}^{+}$and $\mathrm{CD}^{+} \mathrm{T}$ cells in the skin-draining lymph nodes on day 6 (Fig. 3D and E). The levels of cytokines were measured in psoriatic back skin isolated from mice treated with IgG or anti-PD-1 using RT-qPCR. The results demonstrated that enhanced cytokine expression, including that of IL-17, IL-22, IFN- $\gamma$ and TNF $\alpha$, was detected in mice with IMQ-induced psoriasis treated with anti-PD-1 compared with that in mice treated with IgG (Fig. 3F).

$P D-1-F c$ inhibits inflammation in the IMQ-induced psoriatic mouse model. The present study investigated the role of PD-1 in psoriasis inflammation and its therapeutic potential by determining the benefits of recombinant PD-1-Fc therapy on psoriasis progression in IMQ-induced psoriatic mice. The recombinant PD-1-Fc protein (50 $\mu \mathrm{g}$ per injection) exhibited a weak inflammatory response in IMQ-treated mouse (Fig. 4A). The PASI score was measured each day, and the results demonstrated that the PD-1-Fc-treated mice exhibited lower cumulative PASI scores compared with those in the control group $(\mathrm{P}<0.001$ after treatment for 6 days; Fig. 4B). Histopathological examination of skin lesions confirmed that treatment with PD-1-Fc decreased the thickness of the epidermis of mouse back and ears (Fig. 4C). This result suggested that treatment with $\mathrm{PD}-1-\mathrm{Fc}$ reduced psoriatic inflammation. Compared with the control mice, mice treated with PD-1-Fc exhibited decreased percentages of $\mathrm{CD}^{+}$and $\mathrm{CD}^{+} \mathrm{T}$ cells in the skin-draining lymph nodes (Fig. 4D and E). Cytokine levels were detected in mouse back psoriatic skin using RT-qPCR; the results revealed that PD-1-Fc treatment inhibited cytokine expression, including IL-17, IL-22, IFN- $\gamma$ and $\mathrm{TNF} \alpha$, in psoriatic skin compared with that in the control mice (Fig. 4F).

PD-1-Fc and anti-TNF- $\alpha$ exert an additive effect to alleviate psoriatic inflammation. Anti-TNF- $\alpha$ therapy is used in psoriasis treatment to reduce psoriatic inflammation (32). The IMQ-induced psoriasis model was used to confirm the benefits of anti-TNF- $\alpha$, and the resulted demonstrated that anti-TNF- $\alpha$ decreased the epidermal thickness of the mouse psoriatic ear, which is one of the key epidermal parameters to evaluate psoriasis development (Fig. 5A). In addition, the effects of co-treatment with anti-TNF $\alpha$ and PD-1-Fc were assessed. $\mathrm{PD}-1-\mathrm{Fc}$ (50 $\mu \mathrm{g}$ per injection) alone or together with anti-TNF $\alpha$ (50 $\mu \mathrm{g}$ per injection) were administered to IMQ-treated mice with intraperitoneal injections on days 0 and 3 , starting at IMQ treatment initiation; PD-1-Fc treatment enhanced the benefits of anti-TNF- $\alpha$ therapy, and the co-treatment resulted in weaker skin inflammation compared with that of anti-TNF- $\alpha$ treatment alone (Fig. 5B and C).

Flow cytometry was performed to analyze the percentage of $\mathrm{CD}^{+}$and $\mathrm{CD}^{+} \mathrm{T}$ cells in the skin-draining lymph nodes, and the results revealed that compared with anti-TNF $\alpha$ treatment alone, co-treatment with $\mathrm{PD}-1-\mathrm{Fc}$ and anti-TNF $\alpha$ reduced the percentages of $\mathrm{CD}^{+}$and $\mathrm{CD}^{+} \mathrm{T}$-cell in total $\mathrm{CD} 45^{+}$cells (Fig. 5D and E). To determine the potential function of PD-1-Fc in microenvironmental cytokine production, mouse back skin tissues were homogenized after 6 days of IMQ treatment for western blotting and ELISAs. The results demonstrated that the levels of IL-17 and IL-23 were reduced by co-treatment with PD-1-Fc and anti-TNF- $\alpha$ compared with anti-TNF- $\alpha$ treatment alone (Fig. 5F). The ELISA results revealed that PD-1-Fc or anti-TNF- $\alpha$ alone significantly suppressed cytokine IL-17 and IL-23 production (Fig. 5G), which was in agreement with the previous conclusion. In addition, co-treatment with PD-1-Fc and anti-TNF- $\alpha$ further inhibited IL-17 and IL-23 production (Fig. 5G). These results suggested that recombinant PD-1-Fc may be a potential candidate for co-treatment with anti-TNF $\alpha$ in patients with psoriasis.

\section{Discussion}

The results of the present study identified a potential therapeutic strategy for patients with psoriasis. Traditional treatments are insufficient as topical agents usually function in the short-term; phototherapy treatment has high demands for physicians; and methotrexate, PUVA therapy, retinoids and cyclosporine are highly toxic to patients (2). Targeted biologic therapies are considered to be safer and more effective compared with generalized therapies (33). Through the analysis of clinical samples from patients with psoriasis, the present study identified that PD-1 was expressed in human psoriatic lesions, and upregulated PD-1 was associated with the level of psoriatic inflammation, suggesting a potential role for PD-1 in psoriasis development and progression. The results of the present study also demonstrated that PD-1-Fc treatment effectively alleviated IMQ-induced psoriatic inflammation in mice.

T-lymphocyte activation is essential for the maintenance of psoriasis, and multiple mechanisms are involved in T-cell activation (34). PD-1 is bound by its ligands PD-L1 and PD-L2 and inhibits T-cell activity to prevent autoimmunity (23). However, it remains unclear whether deregulation of PD-1 expression is a hallmark of the progression of the autoimmune disease psoriasis (23). The PD-1/PD-L1 mechanism has been extensively studied in the context of understanding T-cell activation and immune checkpoint-targeted therapy (35-37). Immune checkpoint inhibition with anti-PD1 or anti-PD-L1 therapies results in psoriasis exacerbation $(38,39)$. PD-1 expression is detected on the surface of several types of immune cells, including T cells, monocytes, dendritic cells (DCs), natural killer cells, B cells and macrophages $(12,40)$. PD-L1 serves an important role in the regulation of T cell-mediated immunity $(41,42)$. DCs express both the PD-1 receptor and PD-L1 to interact with cells expressing either PD-1 or PD-L1 (43). Pro-inflammatory cytokines and TLR ligands induce DC activation, during which high levels of PD-L1 expression are observed $(44,45)$. PD-L1 is also expressed on the surface 




B
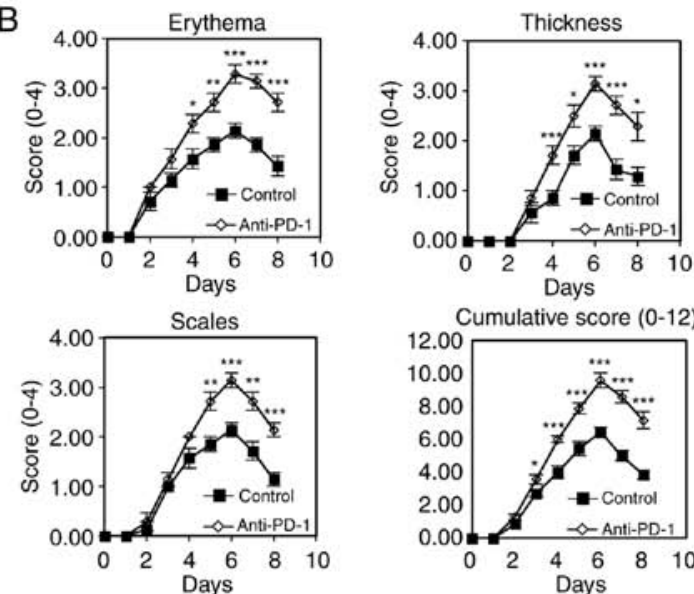

Mouse back skin

C

Day 0
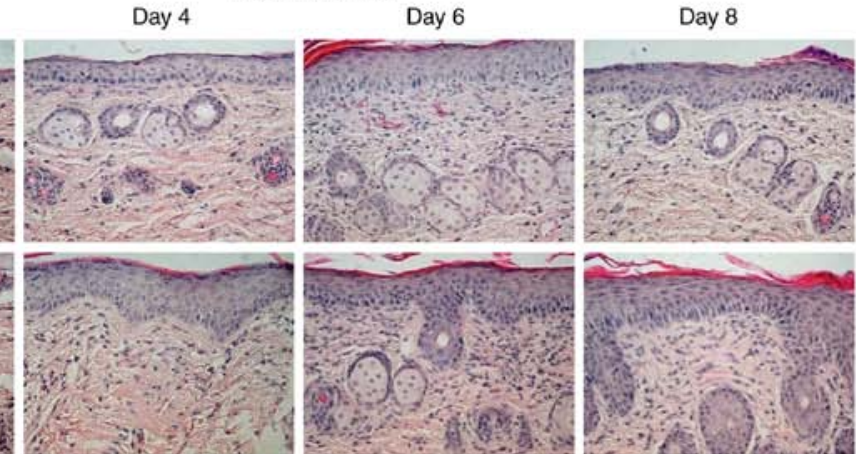

D
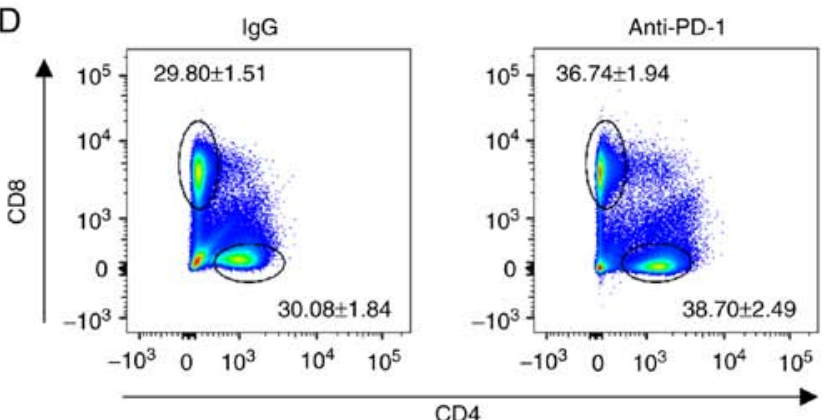

E


$\mathrm{F}$
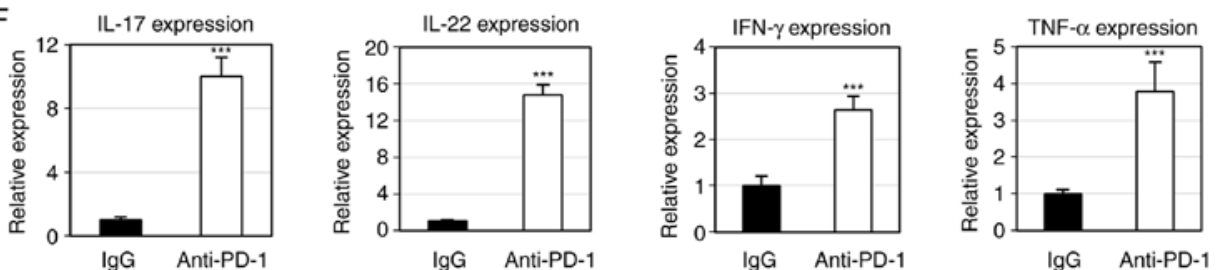

Figure 3. Anti-PD-1 treatment aggravates psoriatic inflammation in mice with IMQ-induced psoriasis. (A) Physical presentations of IMQ-induced mouse dorsal skin in control IgG or anti-PD-1-treated animals. (B) Erythema, thickness, scales and cumulative disease score (mean \pm SD) of five mice/group were evaluated over time. (C) Representative histopathological staining of IMQ-induced biopsies (N=5) harvested from mice treated with anti-PD-1 or IgG after IMQ treatment for 0, 4, 6 and 8 days. (D and E) Representative plots and quantification of flow cytometry analysis of $\mathrm{CD} 4^{+}$and $\mathrm{CD} 8^{+} \mathrm{T}$ cell percentages among the total $\mathrm{CD}_{4} 5^{+}$cells in the skin-draining lymph nodes isolated from mice treated with IgG or anti-PD-1. (F) Reverse transcription-quantitative PCR analysis of the expression of IL-17, IFN- $\gamma$, IL-22 and TNF- $\alpha$ in mouse psoriatic skin lesions. ${ }^{*} \mathrm{P}<0.05,{ }^{* *} \mathrm{P}<0.01,{ }^{* * *} \mathrm{P}<0.001$ vs. IgG. PD-1, programmed cell death 1 ; IMQ, imiquimod; IgG, immunoglobulin G; IL, interleukin; IFN- $\gamma$, interferon $\gamma$; TNF- $\alpha$, tumor necrosis factor $\alpha$. 
A

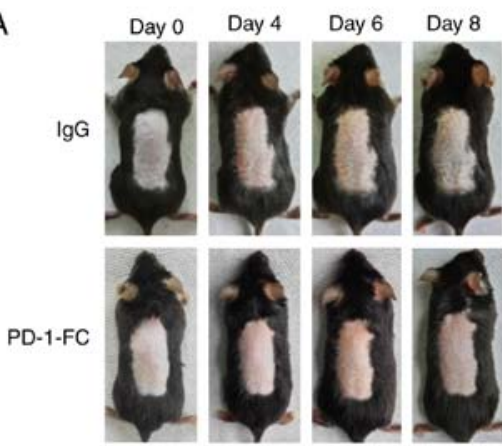

C
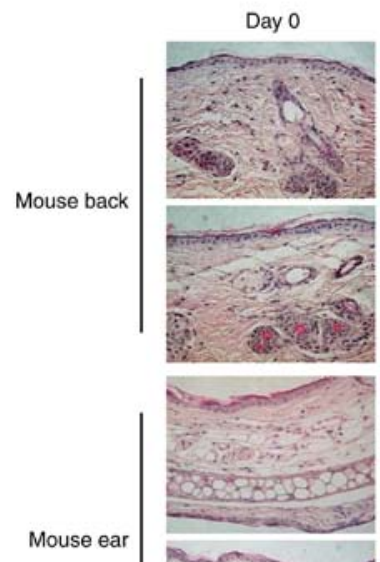

B
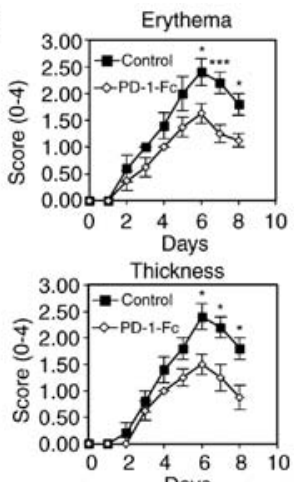

Day 6

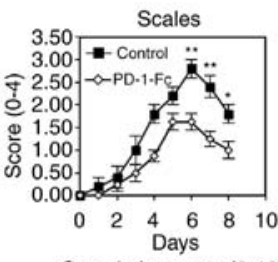

Cumulative score (0-12)

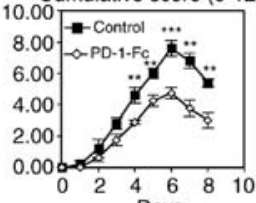

Days

Day 4

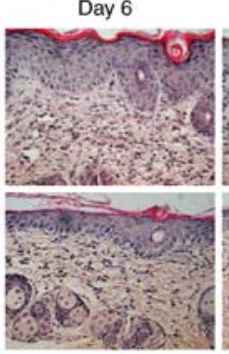

Day 8
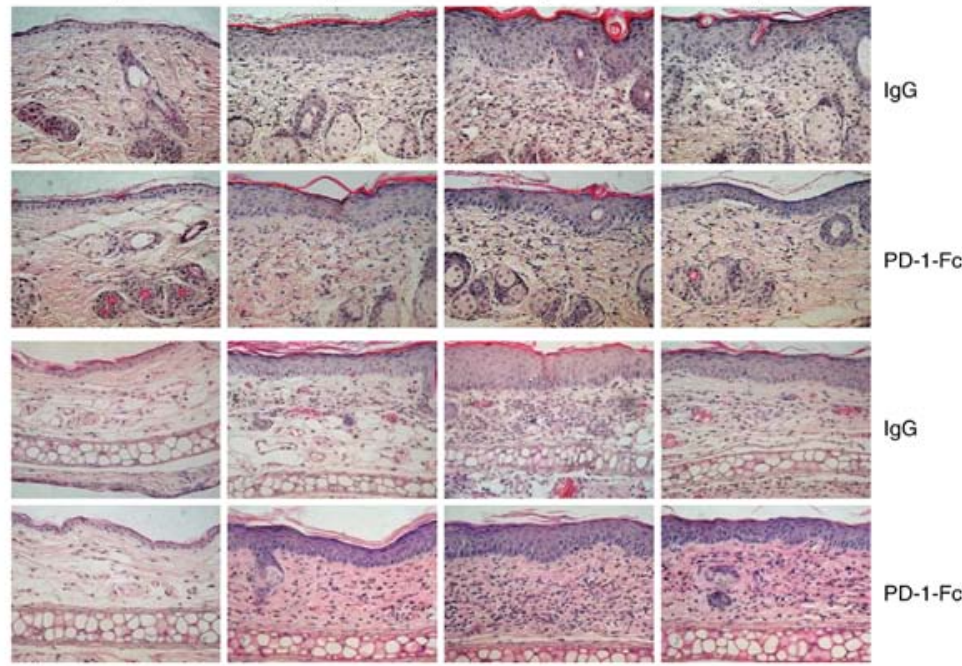

D
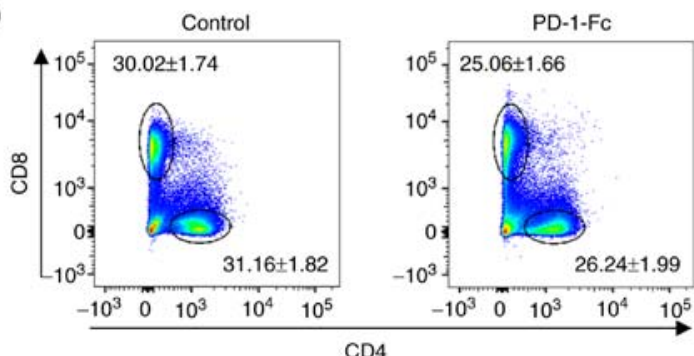

$\mathrm{CD} 4$

E

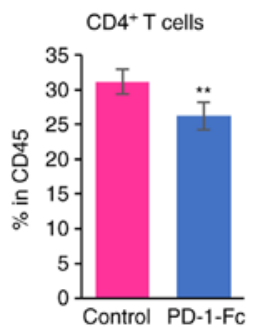



$\mathrm{F}$
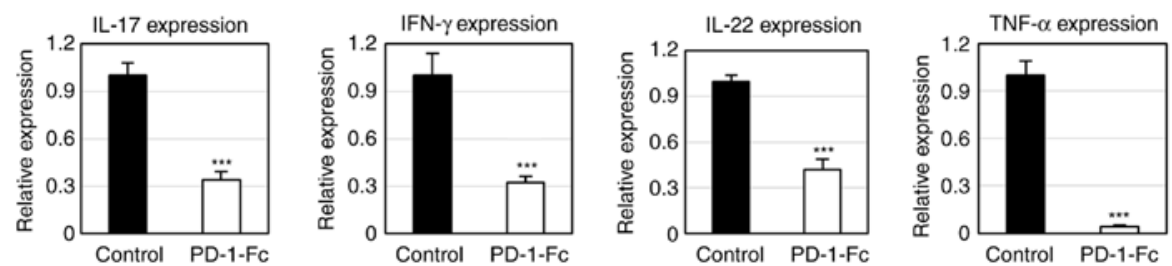

Figure 4. Recombinant PD-1-Fc fusion protein treatment inhibits IMQ-induced psoriatic inflammation. (A-F) IMQ-induced mice were administered PD-1-Fc protein or IgG control. (A) Representative images of IMQ-induced psoriatic dorsal skin from each treatment cohort. (B) Skin erythema, thickness, scales and cumulative disease score were evaluated over time. (C) Representative histopathological staining of IMQ-induced psoriatic skin and ear biopsies over time. $\mathrm{N}=5$. (D and E) Representative plots and quantification of flow cytometry analysis for $\mathrm{CD}^{+}$and $\mathrm{CD} 8^{+} \mathrm{T}$ cell percentages among the total CD45 cells in the skin-draining lymph nodes isolated from mice treated with IgG or PD-1-Fc. (F) The mRNA expression levels of IL-17, IFN- $\gamma$, IL-22 and TNF- $\alpha$ were analyzed by reverse transcription-quantitative PCR in IMQ-induced mouse skin treated with IgG or PD-1-Fc. ${ }^{*} \mathrm{P}<0.05,{ }^{* *} \mathrm{P}<0.01,{ }^{* * * *} \mathrm{P}<0.001$ vs. IgG. PD-1, programmed cell death 1; IMQ, imiquimod; IgG, immunoglobulin G; IL, interleukin; IFN- $\gamma$, interferon $\gamma$; TNF- $\alpha$, tumor necrosis factor $\alpha$. 
A
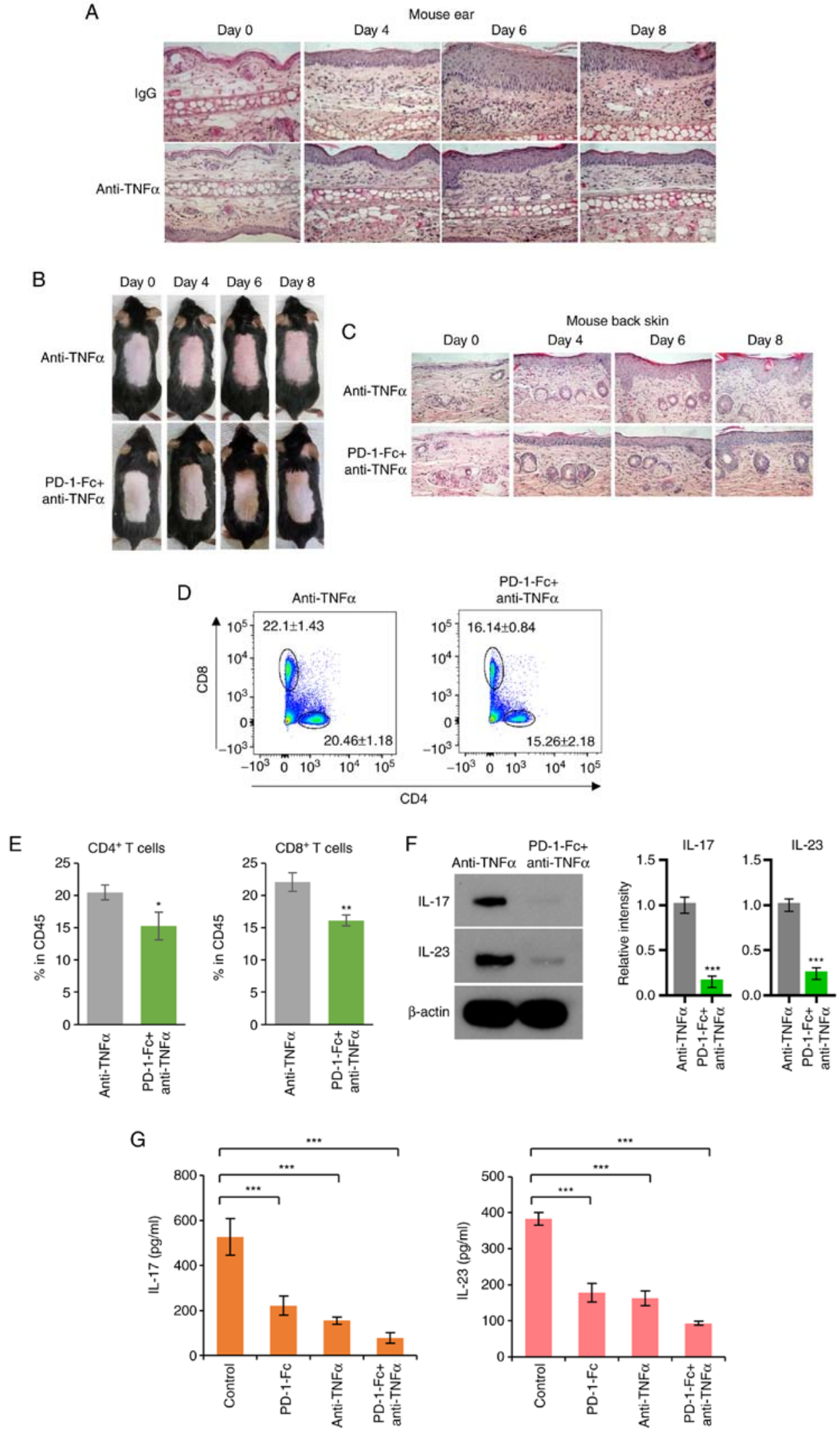

Figure 5. Recombinant PD-1-Fc fusion protein enhances anti-TNF- $\alpha$ efficacy in inhibiting IMQ-induced skin inflammation. (A) Representative histopathological staining of anti-TNF- $\alpha$-treated IMQ-induced mouse ear biopsies after IMQ treatment for $0,4,6$ and 8 days. N=5. (B) Representative images of IMQ-induced mouse dorsal skin treated with anti-TNF- $\alpha$ or PD-1-Fc + anti-TNF- $\alpha$ at the indicated time points. (C) Representative histopathological staining of IMQ-induced mouse psoriasis treated with anti-TNF- $\alpha$ or PD-1-Fc + anti-TNF- $\alpha$ after IMQ treatment for $0,4,6$ and 8 days. N=5. (D and E) Representative plots and quantification of flow cytometry analysis for $\mathrm{CD} 4^{+}$and $\mathrm{CD} 8^{+} \mathrm{T}$ cell percentages among the total $\mathrm{CD} 45^{+}$cells in the skin-draining lymph nodes isolated from IMQ-induced mouse model treated with anti-TNF- $\alpha$ or PD-1-Fc + anti-TNF- $\alpha$. ${ }^{*} \mathrm{P}<0.05,{ }^{* *} \mathrm{P}<0.01$ vs. anti-TNF- $\alpha$. (F) Skin tissue from IMQ-induced mice treated with anti-TNF- $\alpha$ or PD-1-Fc + anti-TNF- $\alpha$ was homogenized for the western blotting assay to detect IL-17 and IL-23 levels; $\beta$-actin was used as the loading control. (G) IMQ-induced psoriatic mice were administered control IgG, PD-1-Fc, anti-TNF- $\alpha$ or PD-1-Fc + anti-TNF- $\alpha$ as indicated, and the skin tissue was homogenized for ELISA assays to detect IL-17 and IL-23 cytokine production. $\mathrm{N}=5$. ${ }^{* * *} \mathrm{P}<0.001$. PD-1, programmed cell death 1; IMQ, imiquimod; TNF- $\alpha$, tumor necrosis factor $\alpha$; IL, interleukin. 
of $\mathrm{CD}^{+}$and $\mathrm{CD} 8^{+} \mathrm{T}$ cells to inhibit their activities (46). However, there is also a co-stimulatory interaction between PD-1 and PD-L1 to promote the development of memory CD4 ${ }^{+}$ $\mathrm{T}$ cells (43). In addition, the function of PD-1 signaling in the crosstalk between DCs and other effector cells, including $\gamma \delta$ $\mathrm{T}$ cells, MDSCs and tumor-associated macrophages, is still unclear (43). The results of the present study demonstrated that PD-1-Fc negatively modulated psoriatic inflammation; the specific signaling pathway involved in this modulation needs to be explored in future studies.

Psoriasis can be induced or exacerbated by certain drugs, such as immune checkpoint inhibitors anti-PD-1 and small molecule TNF- $\alpha$ antagonists in cancer immunotherapy (47). A meta-analysis has reported that patients with psoriasis have a high risk of cancer incidence, as well as cancer-related death (48). The association between cancer and psoriasis may be related to inflammation; psoriasis is a chronic inflammatory skin disease, and chronic inflammation is associated with increased cancer risk (49). Immunomodulatory therapy for psoriasis treatment, which suppresses immunity and helps to reduce psoriasis symptoms, therefore, may decrease the risk of developing cancers (48). PD-L1 has been demonstrated to alleviate psoriatic inflammation, and PD-L1-Fc has exhibited promising benefits in psoriasis treatment (25). Studies have reported that PD-L1 levels serve a key role in the development of effective T cells $(41,42)$.

PD-1 is a T-cell regulator that belongs to the CD28/CTLA-4 superfamily and negatively modulates T-cell activity (7). Treatment with soluble CTLA-4-Ig resulted in $\geq 50 \%$ improvement of Physician's Global Assessment in clinical studies of psoriasis vulgaris (50). The mouse psoriasis model used in the present study was induced with IMQ, a ligand for Toll-like receptor (TLR) 7 and TLR8, which is used to induce immune activity and leads to mouse psoriasis; this mouse model is the most widely used inducible psoriasis model $(27,51)$. Using this model, a previous study has revealed that PD-1 deficiency leads to enhanced dermal inflammation and increased expression of inflammatory cytokines, including IL-17 and IL-22, by innate $\gamma \delta$-low T cells in the IMQ-induced psoriasis mouse model (24). The results of the present study revealed that PD-1-Fc treatment effectively alleviated psoriatic inflammation in the IQM-induced mouse model and has the potential to exhibit synergistic effects with anti-TNF- $\alpha$ treatment.

\section{Acknowledgements}

Not applicable.

\section{Funding}

This study was supported by the National Natural Science Foundation of China (grant nos. 81874470 and 81973860), the National Key Research and Development Program of China (grant no. 2018YFC1705301) and the Shanghai Natural Science Foundation of China (grant no. 19ZR1458700).

\section{Availability of data and materials}

The datasets used and/or analyzed during the current study are available from the corresponding author on reasonable request.

\section{Authors' contributions}

SGP, BZ and XL conceived and designed the study. SGP, MC, XYS, YQZ, TM and HJL performed experimental work, and collected and analyzed the statistical data. SGP, BL, BZ and $\mathrm{XL}$ interpreted the results. SGP, MC, CYC, BZ and XL wrote and edited the manuscript. All authors read and approved the final manuscript.

\section{Ethics approval and consent to participate}

This study was approved by the Institutional Review Boards of the Yueyang Integrated Traditional Chinese and Western Medicine Hospital (approval no. 2016-016). All mouse experiments were performed following procedures approved by the Institutional Animal Care and Use Committee at Beijing Chaoyang Hospital in Capital Medical University in Beijing China (approval no. 2016-A-177).

\section{Patient consent for publication}

Not applicable.

\section{Competing interests}

The authors declare that they have no competing interests.

\section{References}

1. Bowcock AM and Krueger JG: Getting under the skin: The immunogenetics of psoriasis. Nat Rev Immunol 5: 699-711, 2005.

2. Gottlieb AB: Psoriasis: Emerging therapeutic strategies. Nat Rev Drug Discov 4: 19-34, 2005.

3. Nickoloff BJ, Bonish B, Huang BB and Porcelli SA: Characterization of a $\mathrm{T}$ cell line bearing natural killer receptors and capable of creating psoriasis in a SCID mouse model system. J Dermatol Sci 24: 212-225, 2000.

4. Chang JC, Smith LR, Froning KJ, Schwabe BJ, Laxer JA, Caralli LL, Kurland HH, Karasek MA, Wilkinson DI, Carlo DJ, et al: $\mathrm{CD}^{+} \mathrm{T}$ cells in psoriatic lesions preferentially use $\mathrm{T}$-cell receptor V beta 3 and/or V beta 13.1 genes. Proc Natl Acad Sci USA 91: 9282-9286, 1994.

5. Prinz JC, Vollmer S, Boehncke WH, Menssen A, Laisney I and Trommler P: Selection of conserved TCR VDJ rearrangements in chronic psoriatic plaques indicates a common antigen in psoriasis vulgaris. Eur J Immunol 29: 3360-3368, 1999.

6. Vollmer S, Menssen A and Prinz JC: Dominant lesional $\mathrm{T}$ cell receptor rearrangements persist in relapsing psoriasis but are absent from nonlesional skin: Evidence for a stable antigen-specific pathogenic $\mathrm{T}$ cell response in psoriasis vulgaris. J Invest Dermatol 117: 1296-1301, 2001.

7. Ishida Y, Agata Y, Shibahara K and Honjo T: Induced expression of PD-1, a novel member of the immunoglobulin gene superfamily, upon programmed cell death. EMBO J 11: 3887-3895, 1992.

8. Riley JL: PD-1 signaling in primary T cells. Immunol Rev 229: 114-125, 2009.

9. Freeman GJ, Long AJ, Iwai Y, Bourque K, Chernova T, Nishimura H, Fitz LJ, Malenkovich N, Okazaki T, Byrne MC, et al: Engagement of the PD-1 immunoinhibitory receptor by a novel B7 family member leads to negative regulation of lymphocyte activation. J Exp Med 192: 1027-1034, 2000.

10. Latchman Y, Wood CR, Chernova T, Chaudhary D, Borde M, Chernova I, Iwai Y, Long AJ, Brown JA, Nunes R, et al: PD-L2 is a second ligand for PD-1 and inhibits T cell activation. Nat Immunol 2: 261-268, 2001.

11. Sun X, Roudi R, Dai T, Chen S, Fan B, Li H, Zhou Y, Zhou M, Zhu B, Yin C, et al: Immune-related adverse events associated with programmed cell death protein-1 and programmed cell death ligand 1 inhibitors for non-small cell lung cancer: A PRISMA systematic review and meta-analysis. BMC Cancer 19: 558, 2019. 
12. Keir ME, Butte MJ, Freeman GJ and Sharpe AH: PD-1 and its ligands in tolerance and immunity. Annu Rev Immunol 26: 677-704, 2008.

13. Nishimura H, Agata Y, Kawasaki A, Sato M, Imamura S, Minato N, Yagita H, Nakano T and Honjo T: Developmentally regulated expression of the $\mathrm{PD}-1$ protein on the surface of double-negative (CD4-CD8-) thymocytes. Int Immunol 8: 773-780, 1996.

14. Agata $Y$, Kawasaki A, Nishimura H, Ishida Y, Tsubata T, Yagita $H$ and Honjo T: Expression of the PD-1 antigen on the surface of stimulated mouse T and B lymphocytes. Int Immunol 8: 765-772, 1996.

15. Iwai Y, Ishida M, Tanaka Y, Okazaki T, Honjo T and Minato N: Involvement of PD-L1 on tumor cells in the escape from host immune system and tumor immunotherapy by PD-L1 blockade. Proc Natl Acad Sci USA 99: 12293-12297, 2002.

16. Okazaki T, Chikuma S, Iwai Y, Fagarasan S and Honjo T: A rheostat for immune responses: The unique properties of PD-1 and their advantages for clinical application. Nat Immunol 14: 1212-1218, 2013

17. Fourcade J, Sun Z, Benallaoua M, Guillaume P, Luescher IF, Sander C, Kirkwood JM, Kuchroo V and Zarour HM Upregulation of Tim-3 and PD-1 expression is associated with tumor antigen-specific CD8 ${ }^{+} \mathrm{T}$ cell dysfunction in melanoma patients. J Exp Med 207: 2175-2186, 2010.

18. Ott PA, Hodi FS and Robert C: CTLA-4 and PD-1/PD-L1 blockade: New immunotherapeutic modalities with durable clinical benefit in melanoma patients. Clin Cancer Res 19: 5300-5309, 2013

19. Topalian SL, Hodi FS, Brahmer JR, Gettinger SN, Smith DC, McDermott DF, Powderly JD, Carvajal RD, Sosman JA, Atkins MB, et al: Safety, activity, and immune correlates of anti-PD-1 antibody in cancer. New Engl J Med 366: 2443-2454, 2012.

20. Brahmer JR, Tykodi SS, Chow LQ, Hwu WJ, Topalian SL, Hwu P, Drake CG, Camacho LH, Kauh J, Odunsi K, et al: Safety and activity of anti-PD-L1 antibody in patients with advanced cancer. N Engl J Med 366: 2455-2465, 2012.

21. Zhang P and Wu MX: A clinical review of phototherapy for psoriasis. Lasers Med Sci 33: 173-180, 2018.

22. Saurat JH, Stingl G, Dubertret L, Papp K, Langley RG, Ortonne JP, Unnebrink K, Kaul M and Camez A; CHAMPION Study Investigators: Efficacy and safety results from the randomized controlled comparative study of adalimumab vs. methotrexate vs. placebo in patients with psoriasis (CHAMPION). Br J Dermatol 158: 558-566, 2008.

23. Francisco LM, Sage PT and Sharpe AH: The PD-1 pathway in tolerance and autoimmunity. Immunol Rev 236: 219-242, 2010.

24. Imai Y, Ayithan N, Wu X, Yuan Y, Wang L and Hwang ST: Cutting edge: $\mathrm{PD}-1$ regulates imiquimod-induced psoriasiform dermatitis through inhibition of IL-17A expression by innate gammadelta-low T cells. J Immunol 195: 421-425, 2015.

25. Kim JH, Choi YJ, Lee BH, Song MY, Ban CY, Kim J, Park J, Kim SE, Kim TG, Park SH, et al: Programmed cell death ligand 1 alleviates psoriatic inflammation by suppressing IL-17A production from programmed cell death 1-high T cells. J Allergy Clin Immunol 137: 1466-1476.e3, 2016.

26. Langley RG and Ellis CN: Evaluating psoriasis with psoriasis area and severity index, psoriasis global assessment, and lattice system physician's global assessment. J Am Acad Dermatol 51: 563-569, 2004

27. van der Fits L, Mourits S, Voerman JS, Kant M, Boon L, Laman JD, Cornelissen F, Mus AM, Florencia E, Prens EP and Lubberts E: Imiquimod-induced psoriasis-like skin inflammation in mice is mediated via the IL-23/IL-17 axis. J Immunol 182: 5836-5845, 2009.

28. Zhu B, Zhang M, Williams EM, Keller C, Mansoor A and Davie JK: TBX2 represses PTEN in rhabdomyosarcoma and skeletal muscle. Oncogene 35: 4212-4224, 2016.

29. Cui R, Widlund HR, Feige E, Lin JY, Wilensky DL, Igras VE, D'Orazio J, Fung CY, Schanbacher CF, Granter SR and Fisher DE: Central role of p53 in the suntan response and pathologic hyperpigmentation. Cell 128: 853-864, 2007.

30. D'Orazio JA, Nobuhisa T, Cui R, Arya M, Spry M, Wakamatsu K, Igras V, Kunisada T, Granter SR, Nishimura EK, et al: Topical drug rescue strategy and skin protection based on the role of Mclr in UV-induced tanning. Nature 443: 340-344, 2006.
31. Works MG, Yin F, Yin CC, Yiu Y, Shew K, Tran TT, Dunlap N, Lam J, Mitchell T, Reader J, et al: Inhibition of TYK2 and JAK1 ameliorates imiquimod-induced psoriasis-like dermatitis by inhibiting IL-22 and the IL-23/IL-17 axis. J Immunol 193 3278-3287, 2014.

32. Lubrano E, Scriffignano S and Perrotta FM: TNF-alpha inhibitors for the six treatment targets of psoriatic arthritis. Expert Rev Clin Immunol 15: 1303-1312, 2019.

33. Ronholt K and Iversen L: Old and new biological therapies for psoriasis. Int J Mol Sci 18: E2297, 2017.

34. Sibaud V: Dermatologic reactions to immune checkpoint inhibitors: Skin toxicities and immunotherapy. Am J Clin Dermatol 19: 345-361, 2018.

35. Muenst S, Soysal SD, Tzankov A and Hoeller S: The PD-1/ PD-L1 pathway: Biological background and clinical relevance of an emerging treatment target in immunotherapy. Expert Opin Ther Targets 19: 201-211, 2015 .

36. Okazaki T and Honjo T: The PD-1-PD-L pathway in immunological tolerance. Trends Immunol 27: 195-201, 2006.

37. Li X, Xiang Y, Li F, Yin C, Li B and Ke X: WNT/ $\beta$-catenin signaling pathway regulating $\mathrm{T}$ cell-inflammation in the tumor microenvironment. Front Immunol 10: 2293, 2019.

38. Voudouri D, Nikolaou V, Laschos K, Charpidou A, Soupos N, Triantafyllopoulou I, Panoutsopoulou I, Aravantinos G, Syrigos K and Stratigos A: Anti-PD1/PDL1 induced psoriasis. Curr Probl Cancer 41: 407-412, 2017.

39. De Bock M, Hulstaert E, Kruse V and Brochez L: Psoriasis vulgaris exacerbation during treatment with a PD-1 checkpoint inhibitor: Case report and literature review. Case Rep Dermatol 10: 190-197, 2018.

40. He J,Hu Y, Hu M and Li B: Development of PD-1/PD-L1 pathway in tumor immune microenvironment and treatment for non-small cell lung cancer. Sci Rep 5: 13110, 2015.

41. Karunarathne DS, Horne-Debets JM, Huang JX, Faleiro R, Leow CY, Amante F, Watkins TS, Miles JJ, Dwyer PJ, Stacey KJ, et al: Programmed death-1 ligand 2-mediated regulation of the PD-L1 to PD-1 axis is essential for establishing CD4(+) T Cell Immunity. Immunity 45: 333-345, 2016.

42. Ellis JS, Guloglu FB, Tartar DM, Hoeman CM, Haymaker CL, Cascio JA, Wan X, Dhakal M, VanMorlan A, Yahng SH and Zaghouani H: APCs expressing high levels of programmed death ligand 2 sustain the development of CD4 T cell memory. J Immunol 185: 3149-3157, 2010.

43. Versteven M, Van den Bergh JMJ, Marcq E, Smits ELJ, Van Tendeloo VFI, Hobo W and Lion E: Dendritic cells and programmed death-1 blockade: A joint venture to combat cancer. Front Immunol 9: 394, 2018.

44. Ritprajak P and Azuma M: Intrinsic and extrinsic control of expression of the immunoregulatory molecule PD-L1 in epithelial cells and squamous cell carcinoma. Oral Oncol 51: 221-228, 2015

45. Pulko V, Liu X, Krco CJ, Harris KJ, Frigola X, Kwon ED and Dong H: TLR3-stimulated dendritic cells up-regulate B7-H1 expression and influence the magnitude of CD8 T cell responses to tumor vaccination. J Immunol 183: 3634-3641, 2009.

46. Diskin B, Adam S, Cassini MF, Sanchez G, Liria M, Aykut B, Buttar C, Li E, Sundberg B, Salas RD, et al: PD-L1 engagement on $\mathrm{T}$ cells promotes self-tolerance and suppression of neighboring macrophages and effector T cells in cancer. Nat Immunol 21: 442-454, 2020

47. Balak DM and Hajdarbegovic E: Drug-induced psoriasis: Clinical perspectives. Psoriasis (Auckl) 7: 87-94, 2017.

48. Trafford AM, Parisi R, Kontopantelis E, Griffiths CEM and Ashcroft DM: Association of psoriasis with the risk of developing or dying of cancer: A systematic review and meta-analysis. JAMA Dermatol 2019 (Epub ahead of print).

49. Coussens LM and Werb Z: Inflammation and cancer. Nature 420: 860-867, 2002.

50. Abrams JR, Lebwohl MG, Guzzo CA, Jegasothy BV, Goldfarb MT, Goffe BS, Menter A, Lowe NJ, Krueger G, Brown MJ, et al: CTLA4Ig-mediated blockade of T-cell costimulation in patients with psoriasis vulgaris. J Clin Invest 103: 1243-1252, 1999.

51. El Malki K, Karbach SH, Huppert J, Zayoud M, Reissig S, Schüler R, Nikolaev A, Karram K, Münzel T, Kuhlmann CR, et al: An alternative pathway of imiquimod-induced psoriasis-like skin inflammation in the absence of interleukin-17 receptor a signaling. J Invest Dermatol 133: 441-451, 2013. 